\title{
Multi-symptom asthma as an indication of disease severity in epidemiology
}

\author{
L. Ekerljung*, A. Bossios*, J. Lötvall*, A-C. Olin\#, E. Rönmark , G. Wennergren+, \\ K. Torén ${ }^{\S}$ and B. Lundbäck*`
}

ABSTRACT: Epidemiological questionnaires have failed to identify individuals with severe asthma. The extent of symptoms of asthma can, however, be easily established in epidemiology, by identification of multiple symptoms. We hypothesise that reporting of multiple symptoms of asthma reflects uncontrolled disease and is a sign of more severe asthma. The aims of the current study were, therefore, to determine the prevalence and determinants of multi-symptom asthma.

A postal questionnaire was sent to 30,000 randomly selected individuals aged 16-75 yrs. A subgroup underwent clinical examinations. Multi-symptom asthma was defined as reported physician-diagnosed asthma, use of asthma medication, recurrent wheeze, attacks of shortness of breath and at least one additional respiratory symptom.

The prevalence of multi-symptom asthma was $2.0 \%$, and it was more common among females (2.4 versus $1.5 \% ; \mathrm{p}<0.001)$ and those with a body mass index $>30 \mathrm{~kg} \cdot \mathrm{m}^{-2}$. Multi-symptom asthmatics had lower forced expiratory volume in $1 \mathrm{~s}$, higher exhaled nitric oxide fraction and more pronounced hyperresponsiveness. Family history of both asthma and allergy (OR 7.3), and occupational exposure to gas dust or fumes (OR 2.0) were also significant risk factors.

Multi-symptom asthmatics comprise $2 \%$ of the general population; multi-symptom asthma is related to signs of more severe disease and could be used as an epidemiological marker of disease severity.

KEYWORDS: Epidemiology, multi-symptom asthma, population study, risk factors

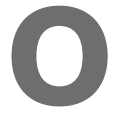
nly a few studies have attempted to identify severe asthma in different populations, which explains why the prevalence of more severe disease is largely unknown [1-4]. Clinical studies suggest that severe asthma is more common among females $[1,2]$ and compared with asthma in general, a greater proportion have neutrophilic inflammation [2, 3]. Occupational exposure has also been shown to be associated with more severe asthma [4]. Asthma with more pronounced severity greatly affects daily life with an impaired quality of life, more frequent premature retirements and an increased risk of hospitalisation and death $[1,5,6]$. Severe asthma also causes the most significant economic burden of asthma, despite representing a minority of those with asthma $[7,8]$.

Studies of severe asthma have primarily been performed in clinical cohorts, as defining severe asthma in population studies has been difficult. Therefore, severe asthma has rarely been studied in population cohorts [9]. Asthma with multiple symptoms, despite the concurrent use of asthma medication, is more readily defined in population studies and could potentially be used as a severity index. The West Sweden Asthma Study (WSAS) presents an opportunity to study severe asthma in a population sample. The WSAS was initiated in 2008 and provides the possibility of studying extensive aspects of asthma epidemiology, including severity [10-12]. The study included a postal questionnaire to a large sample of the general population in West Sweden and clinical investigations of a randomly selected subsample of those with asthma.

The present study aims to determine the prevalence and risk factors of asthma with multiple respiratory symptoms despite the use of asthma medication. A secondary aim was to determine whether the definition of multi-symptom asthma is reflected by clinical manifestations of more severe disease.

\section{MATERIAL AND METHODS}

Study population and participation

The study population has previously been described [10]. In 2008, a questionnaire was
AFFILIATIONS

*Krefting Research Centre, Dept of Internal Medicine, Institute of Medicine, Sahlgrenska Academy, University of Gothenburg, Depts of ${ }^{*}$ Public Health and Community Medicine, Institute of Medicine,

${ }^{\S}$ Environmental and Occupational Medicine, Institute of Medicine, and +Paediatrics, Sahlgrenska Academy, University of Gothenburg, Gothenburg, and

"Obstructive Lung Disease in Northern Sweden (OLIN), Dept of Medicine, Sunderby Central Hospital of Norrbotten, Luleå, Sweden.

CORRESPONDENCE

L. Ekerljung

University of Gothenburg,

Sahlgrenska Academy

Dept of Internal Medicine/Krefting

Research Centre

Box 424

SE-405 30 Gothenburg

Sweden

E-mail: linda.ekerljung@gu.se

Received:

Sept 092010

Accepted after revision:

Jan 162011

First published online:

Feb 102011 
mailed to 30,000 randomly selected subjects aged 16-75 yrs, living in the region of West Gothia, Sweden; 15,000 subjects lived in metropolitan Gothenburg and 15,000 lived elsewhere in West Gothia. The population of the area was one-sixth of the Swedish population in 2007. As some subjects could not be traced, the study sample consisted of 29,218 subjects, of whom $18,087(62 \%)$ subjects responded. A nonresponder study has been performed [11].

\section{Questionnaire}

The questionnaire consisted of three parts: the Obstructive Lung Diseases in Northern Sweden (OLIN) questionnaire; questions on occupation-, retirement- and exposure-related symptoms; and the Swedish version of the Global Allergy and Asthma European Network $\left(\mathrm{GA}^{2} \mathrm{LEN}\right)$ questionnaire $[13,14]$. The questionnaire included questions on asthma, chronic bronchitis/chronic obstructive pulmonary disease (COPD)/ emphysema, rhinitis, eczema, respiratory symptoms, use of asthma medication and possible determinants of disease, such as smoking habits, occupation, airborne occupational exposures and family history of airway diseases.

\section{Clinical examinations}

Clinical examinations were performed in a subsample of the questionnaire respondents. Examinations included skin-prick tests (SPTs), height and weight measurements, exhaled nitric oxide fraction $(F e N O)$ determination at a flow rate of $50 \mathrm{~mL} \cdot \mathrm{s}^{-1}$, spirometry and methacholine challenge. In total, 371 nonasthmatics and 472 asthmatics were clinically investigated. The SPT was performed using a standard panel of 11 inhaled allergens (ALK, Hørsholm, Denmark) (see online depository). A mean wheal diameter equal to or greater than that of the positive control was considered as a positive response. Spirometry was performed (Masterscope; Jaeger, Höchberg, Germany) and the forced expiratory volume in $1 \mathrm{~s}$ (FEV1) \% predicted was calculated. The methacholine challenge was performed using the Spira equipment (Spira Respiratory Care Center Ltd, Hämeenlinna, Finland) and followed a shortened protocol with a highest administered cumulative dose of $1.96 \mathrm{mg}$. The formula used to calculate provocative dose causing a $20 \%$ fall in FEV1 can be found in the online depository. The asthmatics who underwent clinical examinations were classified according the Global Initiative for Asthma (GINA) 2006 classification using frequency of symptoms and lung function [15]. The definitions used for the GINA classification are given in the online depository.

\section{Definition of multi-symptom asthma}

Subjects reporting "physician-diagnosed asthma", "asthma medication", "attacks of shortness of breath", "recurrent wheeze", and at least one symptom out of "dyspnoea", "breathlessness (exertion)", "breathlessness (cold)" or "breathlessness (exertion in cold)" were considered multisymptom asthmatics. For the purpose of this study, all subjects reporting physician-diagnosed asthma but without multisymptom asthma are referred to as having "other asthma". Nonasthmatics did not report physician-diagnosed asthma. The rationale and hypothesis behind the definition of multisymptom asthma, and definitions of diseases, symptoms and possible determinants of disease are given in the online depository.

\section{Analyses}

The prevalence and risk factor calculations were based on all 18,087 questionnaire responders. Presented clinical data were obtained from a subsample of 843 subjects. Statistical analyses were performed using SPSS version 16.0 (IBM, Somers, NY, USA). Comparisons of proportions were tested using Chisquared tests, p-values were calculated using Fisher's exact test and the Mantel-Haenszel test for trend was used where appropriate. Unpaired t-tests were used to compare means between two groups. A p-value of $<0.05$ was regarded as statistically significant. Covariates used in the analyses included family history of asthma and/or allergy, rural/farm childhood, smoking habits, age, sex, area of residence, occupational exposure, and allergic rhinitis. Allergic rhinitis was used as a surrogate variable for atopy. In the logistic regression models, two of the variables, family history of asthma and family history of allergy, were combined. Three logistic regression models were performed. First, the odds ratio (OR) for multi-symptom asthma was calculated using nonasthma as reference group; secondly, other asthma was compared with nonasthma; and thirdly, multi-symptom asthma was compared with other asthma. In addition, a multinomial regression model was created incorporating all three groups. The results can be seen in the online depository. The attributable fraction (AF), i.e. the proportion of cases caused by a specific factor, was calculated according to the formula $((\mathrm{RR}-1) / \mathrm{RR}) \times p$, where $\mathrm{RR}$ is the risk ratio and $p$ is the proportion of exposed cases [16]. RR was calculated according to the formula $(a /(a+b)) /(c /(c+d))$, where $a$ is the number of subjects with multi-symptom asthma exposed to the factor, $b$ is the number of subjects without asthma exposed to the factor, $c$ is the number of subjects with multi-symptom asthma not exposed to the factor and $d$ is the number of subjects without asthma not exposed to the factor.

\section{RESULTS}

\section{Prevalence and symptoms of multi-symptom asthma}

Multi-symptom asthma was detected in $2.0 \%$ of the population. No significant differences were found by age, while it was significantly more common among females than males (2.4 versus $1.5 \% ; \mathrm{p}<0.001)$. Subjects with multi-symptom asthma comprised $24.4 \%$ of subjects with physician-diagnosed asthma. All investigated symptoms were more common among multisymptom asthmatics compared with nonasthmatics, while all symptoms except allergic rhinitis were more common compared with subjects with other asthma (table 1).

\section{Clinical characteristics}

Lung function, expressed as FEV1 \% pred, was lower in both multi-symptom asthma and other asthma versus healthy controls, and lower in multi-symptom asthma versus other asthma (table 2). Of the multi-symptom asthmatics, $82.9 \%$ reacted with a $>20 \%$ decrease in FEV1 to cumulative doses of methacholine up to $1.96 \mathrm{mg}$ compared with $58.7 \%$ of those with other asthma $(p=0.004)$ and $40.1 \%$ of the nonasthmatics $(\mathrm{p}<0.001)$ (table 2 and fig. 1). When this highly positive bronchial challenge was used as a physiological diagnosis of asthma, multi-symptom asthma yielded a positive predictive value of $83 \%$ and a specificity of $94 \%$, while sensitivity was lower $(34 \%)$, as better controlled asthmatics with fewer symptoms often react to relatively low doses of methacholine. 


\begin{tabular}{|c|c|c|c|c|}
\hline \multirow{2}{*}{$\begin{array}{l}\text { TABLE } 1 \\
\text { Symptom }\end{array}$} & \multicolumn{4}{|c|}{$\begin{array}{l}\text { Differences in prevalence of respiratory } \\
\text { symptoms for multi-symptom asthmatics (MSA), } \\
\text { other asthmatics and nonasthmatics }\end{array}$} \\
\hline & & MSA & $\begin{array}{l}\text { Other } \\
\text { asthma }\end{array}$ & Nonasthma \\
\hline \multicolumn{2}{|l|}{ Subjects $\mathrm{n}$} & 367 & 1340 & 16380 \\
\hline \multicolumn{2}{|c|}{ Asthma medication } & $100.0^{\#}$ & 59.2 & 2.4 \\
\hline \multicolumn{2}{|c|}{ Attacks of shortness of breath } & $100.0^{\#}$ & 51.3 & 4.1 \\
\hline \multicolumn{2}{|c|}{ Recurrent wheeze } & $100.0^{\#}$ & 15.3 & 4.1 \\
\hline \multicolumn{2}{|c|}{ Any wheeze } & 100.0 & 56.8 & 12.1 \\
\hline \multicolumn{2}{|l|}{ Dyspnoea } & 41.1 & 16.4 & 5.0 \\
\hline \multicolumn{2}{|c|}{ Dust triggered } & 73.6 & 49.3 & 13.3 \\
\hline \multicolumn{2}{|c|}{ Strong smell triggered } & 63.8 & 38.1 & 10.9 \\
\hline \multicolumn{2}{|c|}{ Exercise triggered } & 78.2 & 48.8 & 15.0 \\
\hline \multicolumn{2}{|c|}{ Cold triggered } & 73.6 & 40.2 & 7.6 \\
\hline \multicolumn{2}{|c|}{ Exercise in cold triggered } & 80.4 & 55.8 & 15.5 \\
\hline \multicolumn{2}{|c|}{ Chronic bronchitis ever } & 22.1 & 10.6 & 2.6 \\
\hline \multicolumn{2}{|c|}{ Chronic productive cough } & 43.6 & 14.7 & 4.5 \\
\hline \multicolumn{2}{|c|}{ Chronic rhinitis } & 56.4 & 35.4 & 17.7 \\
\hline \multicolumn{2}{|c|}{ Allergic rhinitis } & 65.7 & 64.4 & 22.9 \\
\hline \multicolumn{2}{|c|}{$\begin{array}{l}\text { Difficulty breathing after use } \\
\text { of painkiller }\end{array}$} & 13.1 & 5.7 & 1.2 \\
\hline \multicolumn{2}{|c|}{ Tight chest from walking } & 59.1 & 26.6 & 6.5 \\
\hline
\end{tabular}

Data are presented as \%, unless otherwise stated. The p-values for comparisons between MSA and nonasthmatics, MSA and other asthmatics, and other asthmatics and nonasthmatics were all $<0.001$ except for allergic rhinitis (MSA versus other asthmatics; $p=0.653$ ). *: by definition.

Subjects with multi-symptom asthma and other asthma had a higher number of positive SPTs than nonasthmatics, but there were no differences between the two groups of asthma (table 2). There were no differences in the number of positive SPTs between multi-symptom asthmatics and other asthmatics, nor were there any differences in which allergens they reacted to. Obesity was more common in multi-symptom asthma compared with the other two groups. FeNO increased with increasing asthma severity. Morbidity variables, particularly emergency unit visits and asthma exacerbations, were considerably more common in multi-symptom asthma compared with other asthma (table 2). According to the GINA 2006 classification, $59.4 \%$ of subjects with multi-symptom asthma had uncontrolled or poorly controlled asthma, compared with $28.2 \%$ among subjects with other asthma $(\mathrm{p}<0.001)$.

\section{Demographics and exposures}

Multi-symptom asthma was significantly associated with exposure to occupational gas, dust or fumes compared with both nonasthma and other asthma (table 3). Those with multisymptom asthma were more often smokers compared with other asthmatics and non-asthmatics. Those with multisymptom asthma were on average older at disease onset, 25.0 versus 21.6 yrs. There were no differences regarding the population density of the place of residence or rural or farm childhood among the groups. Only $8.0 \%$ of nonasthmatics had a family history of both asthma and allergy while this was true for $29.4 \%$ of those with multi-symptom asthma (table 3 ).

\section{Multivariate relationships}

Having a family history of asthma was the strongest risk factor for multi-symptom asthma compared with nonasthma (OR 7.3, 95\% CI 5.5-9.7). The ORs for having a family history of either asthma or allergy were equally strong (OR 2.6 and 2.7, respectively). Other significant risk factors included occupational exposures (OR 2.0), female sex (OR 1.6), age 61-75 yrs (OR 1.5) and current smoking (OR 1.3) (table 4).

When other asthma was used as a reference category, family history of asthma and smoking no longer appeared as significant risk factors, and age 46-60 yrs emerged as a new significant risk factor. For other asthma, using nonasthma as a reference, female sex was not a risk factor. Old age was a protective factor for other asthma in contrast to multisymptom asthma, where old age was a risk factor.

In an additional analysis, reported allergic rhinitis was added to the model as a surrogate variable for allergic sensitisation and became the strongest single risk factor for multi-symptom asthma (OR 4.9; data not shown). The impact of a family history of allergy was then reduced, while the impact of a family history of asthma did not change. The remaining variables were only marginally affected.

\section{AF and multiple risk factors}

The AF was highest for a family history of allergy, which explained $37.1 \%$ of the multi-symptom asthma in the study population (fig. 2). In addition, a family history of asthma (AF $32.8 \%$ ), female sex (AF 23.7\%), and occupational exposure to gas, dust or fumes (AF 16.9\%) were important explanations for multi-symptom asthma. When the AF for occupational exposure to gas, dust or fumes was calculated for males and females separately, the AF for males was $35.3 \%$ and for females was $12.5 \%$, reflecting the fact that $56.0 \%$ of the males and $24.4 \%$ of the females were exposed at work.

An obvious additive risk effect on OR was seen when analysing the joint effect of family history, occupational exposure and current smoking. Using nonsmoking subjects with no family history of asthma or allergy and no occupational exposure to gas, dust or fumes as a reference, the OR for multi-symptom asthma for subjects with a history of both asthma and allergy, and occupational exposure and/or current smoking was 10.5 (fig. 3).

\section{DISCUSSION}

In the present population study, a subgroup of asthma with multiple symptoms was identified. The prevalence of multisymptom asthma was $2 \%$ in the general population and represented $24 \%$ of all asthma, a result similar to that of the global Asthma Insights and Reality (AIRE) survey, where the proportion of asthmatics with severe persistent asthma was $18 \%$ [1]. We hypothesise that those with multi-symptom asthma were suffering from a more severe disease, as they reported more symptoms due to environmental triggers, such as cold air and dust, had significantly lower lung function, expressed signs of increased airway inflammation, were more hyperresponsive, and had more night-time awakenings compared with those with fewer symptoms of asthma. Environmental load was also more important for multisymptom asthma than for asthma in general, as occupational 
TABLE 2 Clinical characteristics for multi-symptom asthmatics (MSA), other asthmatics and nonasthmatics

\begin{tabular}{|c|c|c|c|c|c|c|}
\hline \multirow[t]{2}{*}{ Variable } & \multirow[t]{2}{*}{ MSA } & \multirow[t]{2}{*}{ Other asthma } & \multirow[t]{2}{*}{ Nonasthma } & \multicolumn{3}{|c|}{ p-values } \\
\hline & & & & $\begin{array}{c}\text { MSA versus } \\
\text { nonasthma }\end{array}$ & $\begin{array}{l}\text { MSA versus other } \\
\text { asthma }\end{array}$ & $\begin{array}{c}\text { Other asthma versus } \\
\text { nonasthma }\end{array}$ \\
\hline Subjects $n$ & 111 & 361 & 371 & & & \\
\hline \multicolumn{7}{|l|}{ Clinical variables } \\
\hline Methacholine PD20 <1.96 mg & 82.9 & 58.7 & 40.1 & $<0.001$ & 0.004 & $<0.001$ \\
\hline \multicolumn{7}{|l|}{ Positive SPTs } \\
\hline 1 & 22.6 & 18.1 & 14.7 & $<0.001^{\circ}$ & 0.959 & $<0.001$ \\
\hline 2 & 10.8 & 10.7 & 5.1 & & & \\
\hline 3 & 8.6 & 10.4 & 1.8 & & & \\
\hline$\leqslant 4$ & 10.8 & 10.7 & 4.0 & & & \\
\hline $20-25$ & 28.7 & 36.6 & 41.1 & & & \\
\hline $25-30$ & 36.4 & 37.2 & 40.8 & & & \\
\hline$\geqslant 30$ & 32.2 & 21.4 & 12.9 & & & \\
\hline \multicolumn{7}{|c|}{$\begin{array}{l}\text { Morbidity variables due to breathing } \\
\text { problems last year }\end{array}$} \\
\hline Visited emergency department & 20.7 & 6.1 & 4.0 & $<0.001$ & $<0.001$ & 0.239 \\
\hline Hospitalised & 4.5 & 1.4 & 1.1 & 0.034 & 0.057 & 0.749 \\
\hline$\geqslant 1$ exacerbation & 34.2 & 12.5 & 1.6 & $<0.001$ & $<0.001$ & $<0.001$ \\
\hline Sick leave & 7.1 & 4.6 & 1.0 & $<0.001$ & 0.063 & $<0.001$ \\
\hline
\end{tabular}

Data are presented as mean \pm SD or \%, unless otherwise stated. Comparisons have been made between groups of asthma using unpaired t-tests (forced expiratory volume in $1 \mathrm{~s}\left(\mathrm{FEV}_{1}\right)$ and exhaled nitric oxide fraction $\left(\mathrm{FeNO}_{\mathrm{NO}}\right)$ ) and Chi-squared tests (remaining variables) for each individual variable listed. \% pred: \% predicted; PD20: provocative dose causing a 20\% fall in FEV1; SPT: skin-prick test; BMI: body mass index. ${ }^{\#}$ : measured at $50 \mathrm{~mL} \cdot \mathrm{s}^{-1}$; ${ }^{\circ}$ : Mantel-Haenszel test for trend. Bold indicated statistically significant $p$-values.

exposure to gas, dust or fumes, as well as smoking, were significant risk factors for multi-symptom asthma. Furthermore, obesity and female sex were more common among subjects with multi-symptom asthma. A family history of asthma and allergy

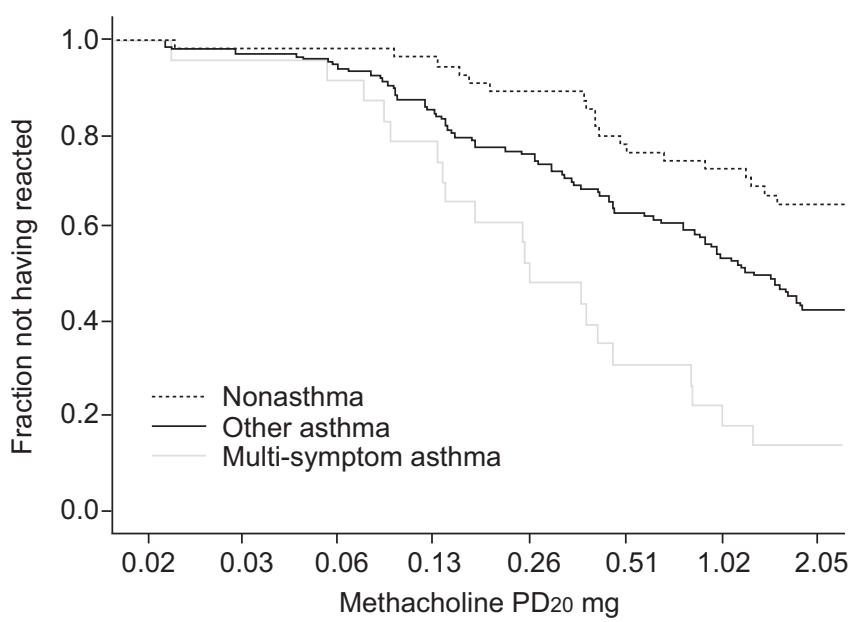

FIGURE 1. Fraction of subjects with nonasthma, other asthma and multisymptom asthma not reacting to an increasing cumulative dose of methacholine. PD20: provocative dose causing a $20 \%$ fall in forced expiratory volume in $1 \mathrm{~s}$. were the strongest risk factors for multi-symptom asthma, particularly if both factors were present.

Frequently present in multi-symptom asthma, hyperresponsiveness, airway inflammation, impaired lung function, nighttime awakenings and dyspnoea are all signs of more severe disease, strengthening the conclusion that an epidemiological definition of multi-symptom asthma will identify subjects with more severe disease. Despite the use of asthma medication, a large majority of the multi-symptom group also had signs of uncontrolled or poorly controlled asthma, as defined by GINA [17]. The definition of multi-symptom asthma used in the current study is not sufficient to encompass all aspects of severe asthma, as previously described in the literature, but many similarities are present. First, "severe asthma" has primarily been investigated in clinical cohorts $[2,4,18-20]$, but rarely in random population cohorts [9]. However, the current study reflects a population with signs of more severe disease and has a sex distribution, with females being more frequently affected, that is similar to what was reported in the populationbased European Community Respiratory Health Survey (ECHRS), where prognostic factors for asthma severity according to GINA were investigated [9], and to the patientbased European Network for Understanding Mechanisms of Severe Asthma (EMFUMOSA) $[2,21]$. In the EMFUMOSA 
TABLE 3 Demographics for subjects with multi-symptom asthma (MSA), other asthma and nonasthma

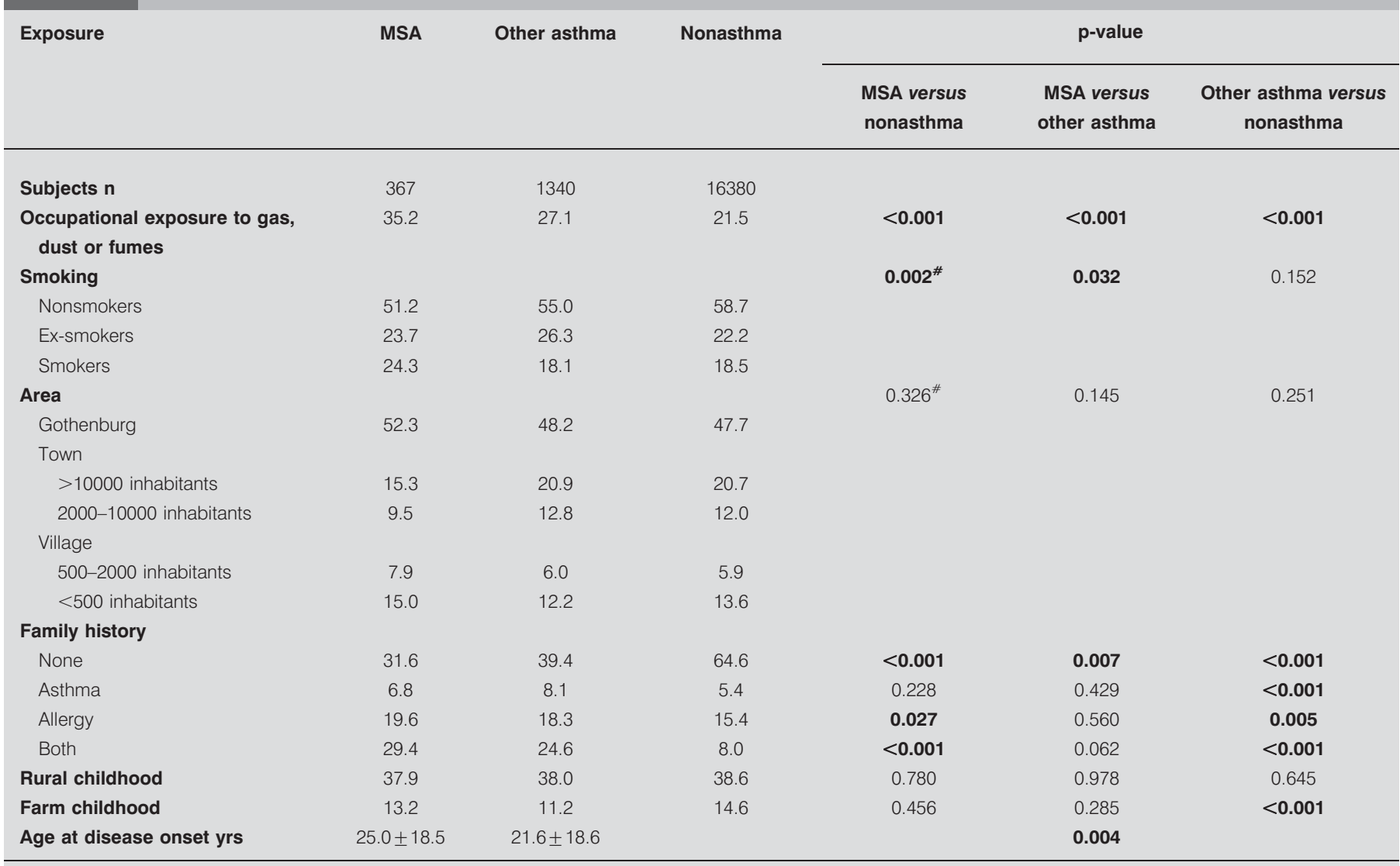

Data are presented as \% or mean \pm SD, unless otherwise stated. Bold indicates statistically significant differences. Comparisons were made between asthma groups using Chi-squared tests for each individual variable listed, except age at disease onset where an unpaired t-test was used. ${ }^{*}$ : Mantel-Haenszel test for trend.

TABLE 4 Risk factors for multi-symptom asthma (MSA) and other asthma as determined by multiple logistic regression analysis Independent variables

Dependent variables

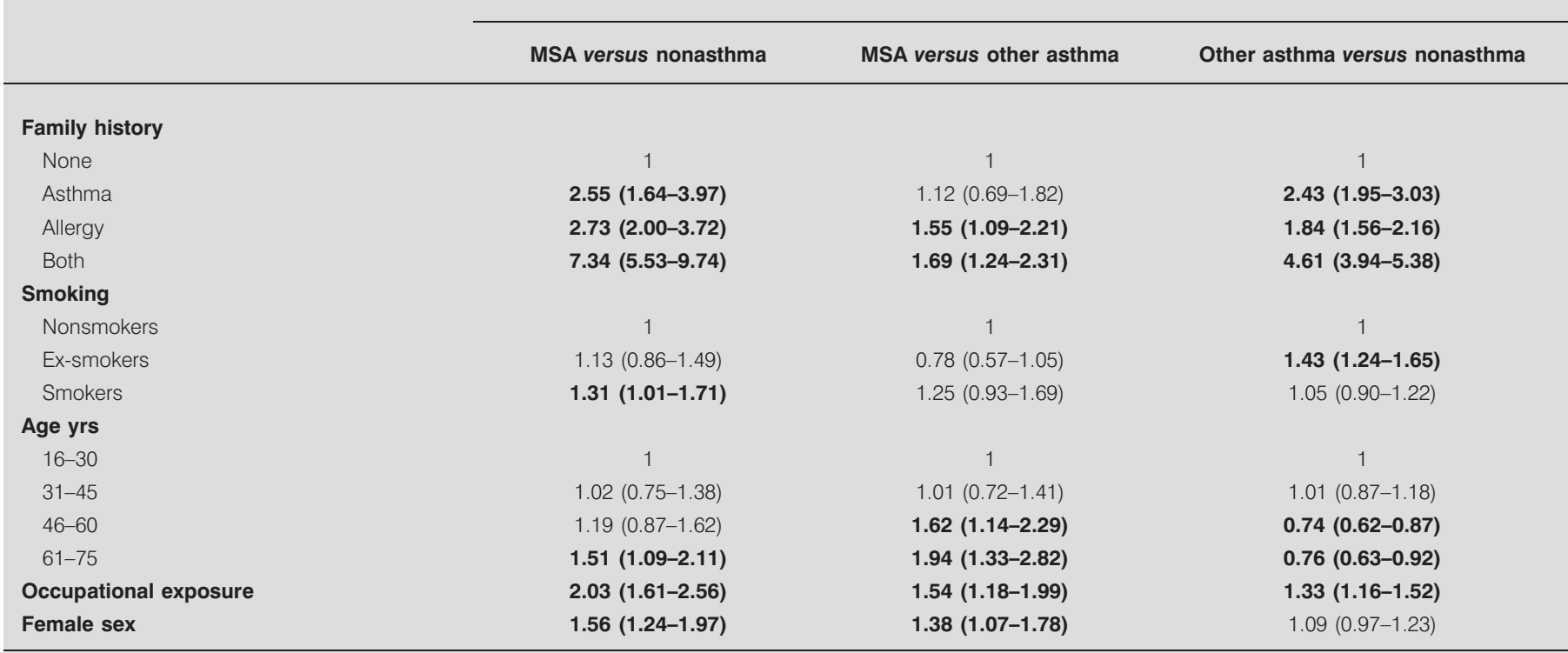

Data are presented as OR $(95 \% \mathrm{Cl})$. Bold indicates statistical significance. All covariates incorporated in the analysis are presented in the table. 


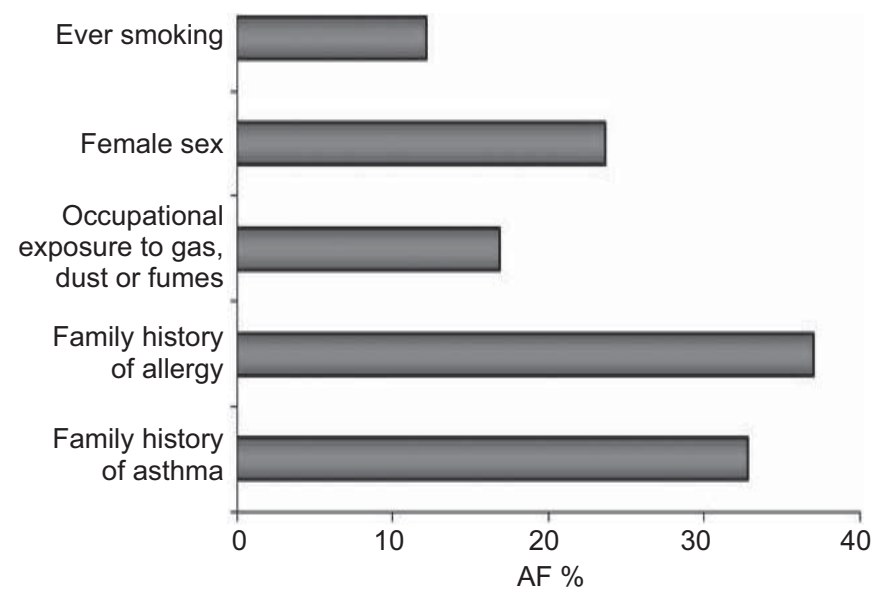

FIGURE 2. Attributable fractions (AFs) for multi-symptom asthma.

study, allergy was inversely related to asthma severity, while in our study and in the ECHRS, no difference in allergic sensitisation was found by asthma severity. The EMFUMOSA study also related severe asthma to lower FEV1\% pred and to a risk of asthma worsening upon aspirin intake [2], relationships also demonstrated in the current study.

The high proportion of asthma with multiple symptoms, despite the use of asthma medication, could be partly explained by the subjective perception of the asthma disease being controlled, despite the presence of symptoms, and therefore reduced use of prescribed medication, leading to the presence of additional symptoms. This assumption is supported by population-based studies showing that many patients with persistent symptoms still consider their disease "well controlled" [1, 19]. The level of asthma control falls short of management goals, with many patients being severely undertreated $[1,19,22]$. In the AIRE study [1], the low usage of preventive medication, with many patients having to resort to quick-relief medication, is indicative of poor asthma control, and a poor correlation between the level of symptoms and perceived asthma control was demonstrated. People with severe asthma are also prone to anxiety and depression, which also is associated with nonadherence to treatment regimens [21, 23, 24]. The level of asthma control is important, as it affects exacerbation frequency and quality of life $[5,17,25,26]$.

Our study shows a stronger relationship between environmental load, heredity components and multi-symptom asthma than has previously been shown for asthma in general. Thus, smoking and occupational exposure to gas, dust or fumes had a greater impact on multi-symptom asthma compared with other asthma. Occupational exposures and air pollutants are known risk factors for asthma [16] and with similar exposures at work, severe asthmatics more frequently reported that work affected their breathing [4, 27]. In particular, having a family history of both asthma and allergy seemed to have a higher importance for multi-symptom asthma than for other asthma. Heredity of allergy was a stronger risk factor for multisymptom asthma compared with other asthma, a result that contrasts with the nonrandom clinical cohort studied in the EMFUMOSA project, where a negative association was reported [2, 27]. While young adulthood is a risk factor for

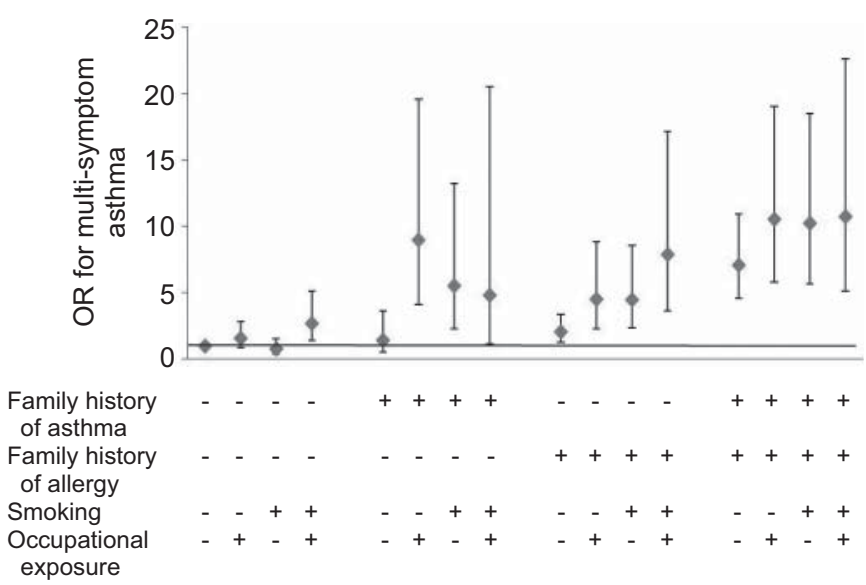

FIGURE 3. The effect of interaction between family history, smoking status and occupational exposure on the odds ratios (ORs) for multi-symptom asthma. —: OR 1; whiskers: $95 \% \mathrm{Cl}$.

asthma in general $[10,28]$, old age was a risk factor for having multi-symptom asthma. Unlike asthma in general [12, 29], no protective effect of a farm childhood could be demonstrated for multi-symptom asthma.

Chronic rhinitis was found to be more strongly related to multisymptom asthma compared with other asthma. It has previously been shown that asthmatics with concurrent rhinitis are at a higher risk for hospitalisations and have a higher cost of asthma medication [30]. According to population studies, $60-80 \%$ of all asthmatics have rhinitis and $20-40 \%$ of all subjects with rhinitis also suffer from asthma $[28,31,32]$. When allergic rhinitis was considered as a determinant of asthma, it appeared as the strongest risk factor for both multi-symptom and other asthma. Rhinitis has also been identified as an important risk factor of incident asthma $[28,33,34]$. In contrast to chronic rhinitis, there was no difference regarding the prevalence of allergic rhinitis among subjects with multi-symptom and other asthma.

The AF, also referred to as the population attributable risk, of ever smoking, female sex, heredity, and occupational exposure to gas, dust or fumes was substantial. The AF for occupational exposure has previously been estimated to be $17.6 \%$ [16]. When investigating subjects with multiple risk factors, we found that the hereditary factors are the most prominent, being related to increased risk of multi-symptom asthma. In the absence of a family history of asthma and allergy, an increased risk at the population level was observed only if both smoking and occupational exposure of gas, dust or fumes were present. If a hereditary factor was present, the concurrent presence of smoking and/or occupational exposure to gas, dust or fumes was considerable, with a 10-fold increased risk of having multi-symptom asthma compared with subjects who had none of the risk factors. It should be noted that the cross-sectional study design did not allow for conclusions regarding causality. The identification of asthma with multiple symptoms and the observed risk factor patterns expands the available measures to reduce disease burden beyond pharmacotherapy. Important risk factors that could be subject to preventive measures are smoking, occupational exposures and obesity. The remaining important risk factors for other asthma in this study were 
female sex and heredity for asthma and allergy. From a clinical perspective, the definition of multi-symptom asthma might be an easy way to identify asthmatics in need of a more thorough follow-up and with additional management needs [17].

This large, randomly selected study population allowed for the identification of preventable risk factors. The use of questionnaire data to define severe or uncontrolled asthma is subject to limitations, which is why we have chosen to use the term multi-symptom asthma. When the present definition of multi-symptom asthma, based on well-defined questionnaire data, was analysed, a group could be identified that differed from other asthmatics with regard to clinical characteristics and risk factor patterns. However, the questionnaire data was not sufficient to distinguish between, for instance, subjects with persistent severe asthma, and subjects with brittle asthma and lack of adherence to treatment. It might be that subjects identified using the current method could be more sensitive to symptoms rather than having a more severe disease. The variables used in the definition of multi-symptom asthma have slightly different time spans as part of their definitions, which might cause symptoms being anterior to asthma medication. However, this should not influence the results to any great extent, as a very small number of asthmatics would have had access to asthma medication before the symptoms arose. It might even be argued that some subjects with multi-symptom asthma may have some features of COPD; however, this is contradicted by the mean age of onset of asthma at $25 \mathrm{yrs}$ and that only nine of the smokers $>50$ yrs had a FEV1/forced vital capacity ratio $<0.7$.

To conclude, multi-symptom asthma comprises $2 \%$ of the general population, and reflects uncontrolled and more severe disease. It is associated with decreased lung function, increased airway inflammation and bronchial hyperresponsiveness. Multi-symptom asthma is associated with a strong hereditary component of family history of both asthma and allergy, female sex and high body mass index. Multi-symptom asthma is also linked to smoking and occupational airborne exposure to gas, dust and fumes, factors that can be prevented to reduce the burden of severe disease. We suggest that multisymptom asthma could potentially be used as an epidemiological marker of severe disease. Identifying patients with severe asthma is important, as they have a higher risk of being hospitalised, have more frequent contacts with healthcare providers and have a higher risk of premature death.

\section{STATEMENT OF INTEREST}

Statements of interest for A-C. Olin, G. Wennergren and B. Lundbäck can be found at www.erj.ersjournals.com/site/misc/statements.xhtml

\section{REFERENCES}

1 Rabe KF, Adachi M, Lai CK, et al. Worldwide severity and control of asthma in children and adults: the global asthma insights and reality surveys. J Allergy Clin Immunol 2004; 114: 40-47.

2 The EMFUMOSA Study Group. The ENFUMOSA cross-sectional European multicentre study of the clinical phenotype of chronic severe asthma. European Network for Understanding Mechanisms of Severe Asthma. Eur Respir J 2003; 22: 470-477.

3 Jatakanon A, Uasuf C, Maziak W, et al. Neutrophilic inflammation in severe persistent asthma. Am J Respir Crit Care Med 1999; 160: 1532-1539.
4 Le Moual N, Siroux V, Pin I, et al. Asthma severity and exposure to occupational asthmogens. Am J Respir Crit Care Med 2005; 172: 440445.

5 Juniper EF, Wisniewski ME, Cox FM, et al. Relationship between quality of life and clinical status in asthma: a factor analysis. Eur Respir J 2004; 23: 287-291.

6 Tough SC, Hessel PA, Ruff M, et al. Features that distinguish those who die from asthma from community controls with asthma. J Asthma 1998; 35: 657-665.

7 Godard P, Chanez P, Siraudin L, et al. Costs of asthma are correlated with severity: a 1-yr prospective study. Eur Respir J 2001; 19: 61-67.

8 Jansson SA, Rönmark E, Forsberg B, et al. The economic consequences of asthma among adults in Sweden. Respir Med 2007; 101: 2263-2270.

9 de Marco R, Marcon A, Jarvis D, et al. Prognostic factors of asthma severity: a 9-year international prospective cohort study. J Allergy Clin Immunol 2006; 117: 1249-1256.

10 Lötvall J, Ekerljung L, Rönmark EP, et al. West Sweden Asthma Study: prevalence trends over the last 18 years argues no recent increase in asthma. Respir Res 2009; 10: 94.

11 Rönmark EP, Ekerljung L, Lötvall J, et al. Large scale questionnaire survey on respiratory health in Sweden: effects of late- and nonresponse. Respir Med 2009; 103: 1807-1815.

12 Wennergren G, Ekerljung L, Alm B, et al. Asthma in late adolescence - farm childhood is protective and the prevalence increase has levelled off. Pediatr Allergy Immunol 2010; 21: 806-813.

13 Heinrich J, Hoelscher B, Frye C, et al. Trends in prevalence of atopic diseases and allergic sensitization in children in Eastern Germany. Eur Respir J 2002; 19: 1040-1046.

14 Lundbäck B, Nyström L, Rosenhall L, et al. Obstructive lung disease in northern Sweden: respiratory symptoms assessed in a postal survey. Eur Respir J 1991; 4: 257-266.

15 Global Initiative for Asthma. Global Strategy for Asthma Management and Prevention. Gaithersburg, GINA, 2009.

16 Torén K, Blanc PD. Asthma caused by occupational exposures is common - a systematic analysis of estimates of the populationattributable fraction. BMC Pulm Med 2009; 9: 7.

17 Global Initiative for Asthma. Global Strategy for Asthma Management and Prevention.www.ginasthma.org/pdf/GINA_Report_2010. pdf Date last accessed: August 17, 2010. Date last updated: 2010.

18 Ponte EV, Franco R, Nascimento HF, et al. Lack of control of severe asthma is associated with co-existence of moderate-to-severe rhinitis. Allergy 2008; 63: 564-569.

19 Rabe KF, Vermeire PA, Soriano JB, et al. Clinical management of asthma in 1999: the Asthma Insights and Reality in Europe (AIRE) study. Eur Respir J 2000; 16: 802-807.

20 Haldar P, Pavord ID, Shaw DE, et al. Cluster analysis and clinical asthma phenotypes. Am J Respir Crit Care Med 2008; 178: 218-224.

21 Chung KF, Godard P, Adelroth E, et al. Difficult/therapy-resistant asthma: the need for an integrated approach to define clinical phenotypes, evaluate risk factors, understand pathophysiology and find novel therapies. ERS Task Force on Difficult/TherapyResistant Asthma. European Respiratory Society. Eur Respir J 1999; 13: 1198-1208.

22 Janson C, Chinn S, Jarvis D, et al. Physician-diagnosed asthma and drug utilization in the European Community Respiratory Health Survey. Eur Respir J 1997; 10: 1795-1802.

23 Heaney LG, Conway E, Kelly C, et al. Predictors of therapy resistant asthma: outcome of a systematic evaluation protocol. Thorax 2003; 58: 561-566.

24 Robinson DS, Campbell DA, Durham SR, et al. Systematic assessment of difficult-to-treat asthma. Eur Respir J 2003; 22: 478-483.

25 Chen H, Gould MK, Blanc PD, et al. Asthma control, severity, and quality of life: quantifying the effect of uncontrolled disease. J Allergy Clin Immunol 2007; 120: 396-402. 
26 Juniper EF. Effect of asthma on quality of life. Can Respir J 1998; 5: Suppl. A, 77A-84A.

27 Gaga M, Papageorgiou N, Yiourgioti G, et al. Risk factors and characteristics associated with severe and difficult to treat asthma phenotype: an analysis of the ENFUMOSA group of patients based on the ECRHS questionnaire. Clin Exp Allergy 2005; 35: 954-959.

28 Lundbäck B. Epidemiology of rhinitis and asthma. Clin Exp Allergy 1998; 28: Suppl. 2, 3-10.

29 Braun-Fahrländer C, Gassner M, Grize L, et al. No further increase in asthma, hay fever and atopic sensitisation in adolescents living in Switzerland. Eur Respir J 2004; 23: 407-413.

30 Price D, Zhang Q, Kocevar VS, et al. Effect of a concomitant diagnosis of allergic rhinitis on asthma-related health care use by adults. Clin Exp Allergy 2005; 35: 282-287.
31 Braman SS, Barrows AA, DeCotiis BA, et al. Airway hyperresponsiveness in allergic rhinitis. A risk factor for asthma. Chest 1987; 91: 671-674.

32 Leynaert B, Bousquet J, Neukirch C, et al. Perennial rhinitis: an independent risk factor for asthma in nonatopic subjects: results from the European Community Respiratory Health Survey. J Allergy Clin Immunol 1999; 104: 301-304.

33 Kanani AS, Broder I, Greene JM, et al. Correlation between nasal symptoms and asthma severity in patients with atopic and nonatopic asthma. Ann Allergy Asthma Immunol 2005; 94: 341-347.

34 Rönmark E, Andersson C, Nyström L, et al. Obesity increases the risk of incident asthma among adults. Eur Respir J 2005; 25: 282-288. 